\title{
Alexander Pisarev
}

\section{The Conflict of Immortalities: The Biopolitics of the Cerebral Subject and Religious Life in Altered Carbon}

Translation by Isaac Stackhouse Wheeler

DOI: https://doi.org/10.22394/2311-3448-2020-7-1-25-46

Alexander Pisarev - Institute of Philosophy, Russian Academy of Science (Moscow, Russia). topisarev@gmail.com

This article explores a possible conflict between the practical and ethical implications of scientific and religious discourses about human nature proposed in the sci-fi series "Altered Carbon." It discusses the clash between biopolitically implemented technology and religious life. The scientific discourse is represented by the "ideology of the cerebral subject" (F. Vidal, F. Ortega), which establishes the connection between the brain and the self. A brief examination of examples of the representation of this ideology in science fiction and its general logic follows. The final development of neuroscience in this series is the technology of uploading the self onto a digital medium, which makes it possible to achieve a quasi-immortal state by changing bodies. This technology, biopolitically appropriated and introduced into individual lives by the state, conflicts with the religious life of Neo-Catholics who refuse to transfer their selves into another body after their bodily deaths. Thus, the field of collision between the interference of science-inspired biopower into the life of the individual and his or her religious life is marked by the coordinates of life and death. The article discusses this fundamental collision, its biopolitical background, and its implications.

Keywords: cerebral subject, brain, science fiction, biopolitics, death, soul, religion.

\section{Introduction}

CIENCE fiction, as understood for the purposes of this article, is
a space of cultural and philosophical experimentation that delves
into an invented version of the world (Kuznetsov 1993; Kuznets- 
ov 2010). Whether in film, video games, or literary works, science fiction traces out radical consequences from developing or incipient scientific and socio-political trends, risks, ideas, and technologies. By transforming the world's social, political, and human configuration, these consequences structure the image of the future it expounds. The future worlds of science fiction are, however, rarely entirely or even primarily fictional, since they are, after all, genetically connected with the real world. Important features of the author's contemporary world are preserved in science fiction worlds. These worlds offer the reader or viewer a thought experiment that is not limited by the stringent requirements, which shackle them in the scientific realm. A science fiction experiment gains credibility due to the fact that the reader or viewer easily recognizes it as a version of their own world. In that sense, science fiction is an instrument of social imagination.

Religion and religious life are also a subject of science fiction experimentation. In many works, religion and the religious life of individuals are transformed on the basis of future events, such as technological or scientific development, an alien invasion, a transformation of human nature, a change in the political sphere, etc. . . The subject of interest here is the interaction between scientific ontologies of selfhood, instrumentalized by a biopolitical authority, and religious concepts and practices. Interest in man, specifically man's transformations and how man's life is managed, have long been characteristic of science fiction. It is no accident that one of the first quintessential science fiction works was Olaf Stapledon's novel First and Last Men (1930), a narrative of the history of the transformation of the human race over millions of years, as it undergoes a wide variety of bodily, spiritual, and intellectual metamorphoses, sees civilization rise and fall several times, and migrates to other planets (Stepldon [Stapledon] 2004).

\section{Discourses on Man}

When speaking of man, we are always operating within the bounds of a particular form of knowledge about man - religious, scientific, everyday, etc. . . As such, the reconstruction of what a human being is remains inextricable from the practices of archaeological and genealogical investigation. Michel Foucault's 1966 work, The Order of Things: An Archaeology of the Human Sciences, is one of the most prominent examples of those reconstructions. Foucault found that what twentieth-century people understood as man was "only a recent invention, a figure not yet two centuries old, a new wrinkle in our knowledge, and 
that he will disappear again as soon as that knowledge has discovered a new form" (Foucault 2005, xxv). In Foucault's reconstruction, which is based on an analysis of the history of the positive sciences and decidedly not of philosophy, a fully secular person is in a historically contingent configuration of positive knowledge, the point of intersection of three sciences - of labor, of life, and of language. Thus, man is discussed in terms of the sciences that study man: conflicts and rules, norms and functions, systems of knowledge and cultural meanings. Labor, language, and life are given to man as the empirical contents of man's experience; they simultaneously precede man's existence and shape man's cognition, functioning like the shadowy, inverse side of thought. According to Foucault, "the modern cogito does not reduce the whole being of things to thought without ramifying the being of thought right down to the inert network of what does not think" (Foucault 2005, 353). Comprehending the products of labor and production, words and speech, the body and the activities of daily life, man finds in them the condition and source of thought, which dwindles to the point that it is not, in itself, thought, but rather social structures, language, genetic code, and flesh, all of which lay claim to that status of "human nature."

During the course of this text, Foucault makes a remark that led to the thinker's later work, an extensive project on the study of ethics and technology of self-regard, which, in turn, laid the foundation for the field of "governmentality studies" (Dean 2010). Foucault realized that "it is reflection, the act of consciousness, the elucidation of what is silent, language restored to what is mute, the illumination of the element of darkness that cuts man off from himself, the reanimation of the inert - it is all this and this alone that constituted the content and form of the ethical" (Foucault 2005, 357). In other words, in a modern, secular society, perceiving human nature entails creating an ethic. According to Foucault, our age is morally impoverished because thinking about the unthinkable, as embodied in the positive sciences, has become an ethic in and of itself. Positive knowledge of human nature cannot be neutral; it either liberates or subjugates. Logos lays claim to the production of ethos, despite the delimitations established by Kant's critiques. It is only by fathoming human nature through the sciences that one has an opportunity to align oneself with it, achieve liberation, and structure one's behavior in accordance with it.

Scientific knowledge of human nature produces ethics as "the kind of relationship you ought to have with yourself, rapport a soi, which I call ethics, and which determines how the individual is supposed to 
constitute himself as a moral subject of his own actions" (Foucault 1997, 263). This definition includes the duality of self-knowledge; the individual can self-construct or be constructed by various echelons of power. According to Foucault, control over oneself and over others are based on self-knowledge.

Power, thus, wields positive knowledge of human nature as a weapon, one that became scientifically supported in the nineteenth century. It studies individuals with the objective of interfering in their lives and optimizing them, eliminating randomness, risks, and shortcomings. Through this process, it becomes "biopolitics" or "biopower," assuming the authority to, as Foucault put it, "make live and let die" (Foucault 2003, 241). The discourse around man, government of the self (i.e ethics), and governing others (i.e government and biopolitics) is a kind of triangle that posits the coordinates for further analysis. In this article, that analysis will be dedicated to the conflict between biopolitics and religious life.

In interpreting human nature, the sciences offer their versions of essentialism (e.g. genetic, mechanical, cerebral, etc. . .). Religious discourses were once dominant in this field, then in the age of secularism, they were largely driven out of the commonly accepted public sphere and into the domain of the private, or otherwise compelled to reach an accommodation with scientific and quasi-scientific discourses that have become commonly accepted in the Western world. We understand ourselves predominantly through working objects and propositions of science, even if they are distorted to the point of unrecognizability by the vicissitudes of the process of transmission and circulation of scientific knowledge (about genes, the brain, the body as a functional system, the microbiome), and we correct our self-understanding and practices in accordance with the latest scientific discoveries and associated technologies. These notions and practices are not always the individual's choice; they may be imposed through education, healthcare or social welfare systems, aggressive marketing, the configuration of urban infrastructure, etc. . They are the embodiment of secular culture, at the center of which sits science, comprehending the world and changing human life.

As the anthropologist Paul Rabinow has noted, man is a creature that suffers from an abundance of discourses and knowledge about itself, an abundance that is not subject to any Logos (Rabinow 2002).

1. Since the definition used here is the one given by Foucault, biopower and biopolitics as its actualization, are generally treated as interchangeable terms. 
The individual's self-understanding is neither a worldview nor a monolithic, non-contradictory system, but rather a bricolage of combined practices with heterogeneous parts that mobilize in different situations and contexts. Some mobilize in response to the search for an answer to the question "who am I and what should I do with my life," while others do so in response to more specific, pragmatic ends (e.g. therapy and the relief of suffering or achieving efficiency, happiness, etc. ..). It is largely thanks to this that an individual is, to a certain extent, able to appropriate and accept mutually contradictory forms of knowledge about him or herself and find a place for them in his or her life. The limits of the convergence of religious and scientific discourse and their practical consequences in the life of a person of faith, and the potential conflict between them, as modeled in science fiction, are the focus of this article.

\section{The Ideology of the Cerebral Subject}

More specifically, this article will discuss one of the strongest contemporary discourses on human nature, neuroessentialism, which links the self with the brain. It will be analyzed using the concept of the ideology of the cerebral subject, developed by sociologists and historians Fernando Vidal and Francisco Ortega on the basis of contemporary and historical material (Vidal 2009; Vidal and Ortega 2011; Vidal and Ortega 2017). The nucleus of the cerebral subject is an inextricable connection between the brain and the self, or the person. That connection can be expressed by the following formula: person $\mathrm{P}$ is identical to person $\mathrm{P}^{*}$ if, and only if, $\mathrm{P}$ and $\mathrm{P}^{*}$ have the same functional brain. In other words, the brain acts as a somatic boundary between a personal and his or her life. The idea of the cerebral subject necessarily involves two progressions of thought. The first is from the empirical fact that we cannot be ourselves without our brains to the metaphysical thesis that we are our brains. Thus, we become "cerebral subjects," not only having brains but being brains. The second transition is from the scientifically correct thesis that there is a correlation between the states of the brain and the states of consciousness to the aggressive and as-of-yet unproven thesis that there is a cause-and-effect relationship between them.

The concept of such a connection between brain and person has become the default for the secular Western world. In both popular culture and the sciences, the brain has practically become the unopposed candidate for the locus of the self. Any attempt to argue seriously that 
the human self is connected with the soul or some other extrascientific source is perceived as eccentric behavior, a poetic expression, the product of "romanticism," or perhaps religiosity, but in any case the conversation is essentially terminated at that point. There is no other part of the body (the lungs or heart, for example), manifestation of humanity (emotion or memory), or metaphysical origin (the soul) that has been as successful as the brain at forming an alliance first with philosophy and then with neuroscience.

As Vidal and Ortega demonstrate, the history of the cerebral subject is far older than neuroscience; it took shape gradually in the seventeenth and eighteenth centuries, following the rejection of Aristotelian psychology in the work of René Descartes, John Locke, Charles Bonnet, and other scientists and philosophers. The details of the connection between the brain and self were clarified over time; it moved into the domain of the natural sciences, reinforcing itself through the accretion of scientific facts, theories, hypotheses, striking imagery (from the phrenological atlas to fMRI scans of the brain), and technologies. Thanks to technological progress in the area of logging the state of the brain, the development of neuroscience saw a qualitative leap in the 1980 s and 1990s, strengthening the "brain-person" connection and reinforcing its position as a discipline that acted in the public interest and shed light on human nature.

The cerebral subject, which had already penetrated into popular culture at the beginning of the twentieth century, strengthened its position during the 1980 os and 1990s. For example, there were more and more films and television series with plots that included the cerebral subject or themes focusing on the cognitive aspects of human nature. ${ }^{2}$ The titles of instructional and popular science lectures, courses, books, and articles also presented the brain as the true subject behind the actions of an individual, the most human part of a human being: "the ethical brain," "the social brain," "how our brains make us do stupid things," "how your brain keeps you safe," "your brain is deceiving you," "we are our brains," "how our brains make us who we are," "the liberated brain," "the rules of the brain," etc. . . In recent decades, subjectivities have become more and more neurologized, as more and more practices are defined and redefined in reference to neuroscience and the brain. The concept of the brain as the site of the self is

2. For a catalogue of films of this kind, see the Cognitive Science Film Index, compiled by employees of the Cognitive Science Department at University of California San Diego. [https://www.indiana.edu/ cogfilms/, accessed on 12.06.2019]. 
used to make decisions on how to nurture, correct, and control oneself and others.

The brain is regarded as more and more responsible for who we are, what we can know, what we can aspire to, and what we must do. Furthermore, in many countries, it has redefined death by becoming the site where it occurs. Beliefs about the brain and its connection with the human self that circulate outside the academy are often far removed from scientific knowledge and are actually distortions or absolutizations of the facts, hypotheses, and promises of neuroscience, which itself occasionally corroborates and nourishes extra-scientific discourses. The cerebral subject was born before contemporary science, and though it is analyzed in its laboratories and institutes, it continues to travel well beyond them, making the range of distinct forms it has taken truly impressive.

The ideology of the cerebral subject can be found in many discourses and practices, permeating the lives of individuals, conforming them to new norms, or, alternatively, old norms that have been rebranded with the help of lexicon and the authority of neuroscience. It may be called an ideology, since it imposed historically contingent and contextually conditioned concepts, values, and practices that are naturalized as self-evident on the basis of individuals' belief that they are their brains. This belief structures the range of these individuals' potential actions and the meanings attributed to them.

The ideological space of the cerebral subject is heterogeneous and not at all confined to libraries and universities. At one pole are multi-billion-dollar scientific projects, such as the Human Brain Project (2013) and the BRAIN Initiative (2013), while at the other are numerous self-help books and courses on efficiency and personal growth, neuromarketing, neurotheology, neurobics, and neuroasceticism. The results (and associated interpretations), hypotheses, and promises of neuroscience are seized upon by widely varying agencies and actors, including other scientific disciplines, and then used at their own discretion. The brain is becoming an explanatory resource, to which social, cultural, and gender differences can be attributed; it is to the brain that people go to search for the key to happiness, a harmonious existence, responsible behavior, normality, and efficiency. As if by magic, the prefix "neuro" makes practically anything persuasive, credible, and deserving of attention and financing. In various ways, the neurosciences and their working objects are penetrating into individuals' psychological, spiritual, and everyday lives, including their most intimate thoughts and affairs, encouraging them to interpret more and 
more manifestations of their own selves through the optics of the cerebral subject. For the bulk of religious people in the West, however, the ideology of the cerebral subject is easy to tolerate, as are neuroscience and the medical technologies based on its findings. In the domain of practical situations, they have seldom come into conflict with the doctrine of the soul as the basis of personhood.

The mounting intrusion of the positive sciences, and the neurosciences in particular, into the lives of individuals, whether through private choice or via biopolitical compulsion, however, is a domain of potential conflict with the religious lives of people of faith, particularly as the sciences trace out the coordinates of life and (perhaps primarily) death. Equipped with scientific knowledge, biopower lays claim to the right to redefine and subordinate these coordinates, and thereby potentially collides with the concepts and practices involving death in the Abrahamic religions. According to Foucault:

What once (and until the end of the eighteenth century) made death so spectacular and ritualized it so much was the fact that it was a manifestation of a transition from one power to another. Death was the moment when we made the transition from one power - that of the sovereign of this world - to another - that of the sovereign of the next world. We went from one court of law to another, from a civil or public right over life and death, to a right to either eternal life or eternal damnation (Foucault 2003, 247).

The biopolitical mode of power, however, interrupts that transition and attempts to keep death within the orbit of its own activity and the self within this world.

Thought experiments that make it possible to model such conflicts can be found in science fiction. The next section will offer a brief analysis of examples of popular science fiction films, in which the cerebral subject plays an important role in the plot and maintains the connection between personality and brain, despite radical bodily transformations. Two primary types of films dealing with the brain will be of particular interest: one subset shows the personality being transferred via a brain transplant, while the other shows the brain being extracted from the body and placed in an artificial life support system that enables it to exist independently. This sequence of emancipating the brain as the medium containing the personality leads directly to the "logical endpoint" of this article, as represented in the series Altered Carbon in its first season - the idea of uploading the brain onto a digital 
medium as the fulfilment of the most extreme promises of the ideology of the cerebral subject. This series will serve as an example for the purposes of evaluating the potential conflict between mind uploading technologies in the hands of biopolitical authorities and religious life based on the doctrine of the soul. This conflict unfolds within the coordinates of life, death, and control.

\section{Where Goes a Brain, There Goes a Person}

The classic film about the brain is James Whale's Frankenstein (1931), based on Mary Shelley's gothic science fiction novel Frankenstein, or the Modern Prometheus (1818). It was the first entry in a popular series of films about Doctor Henry Frankenstein and the Doctor's creature. The film was a gnostic drama of the demiurge and its creation and was also one of the first films to feature a brain transplant. The plots of such films generally center on intra- and inter-species transplantation of brain $\mathrm{X}$ into body $\mathrm{Y}$ and the fate of the resulting hybrid.

Frankenstein includes an additional plotline not found in the literary work, on which it was based, which involves the other man's brain being transplanted into doctor's creature, and how that fact affects its future exploits. This plotline begins in an auditorium at the University of Geneva, where Doctor Waldman presents two surgically removed brains to the audience, one normal and one supposedly dysfunctional. In commenting on the inferiority of the latter, Waldman notes that its visible features - the small number of convolutions in the frontal area and the deformed middle frontal gyrus - correspond to the cruel, criminal life of its former owner. Subsequently, an assistant's blunder causes that "criminal" brain to wind up in the laboratory of Waldman's student, Doctor Frankenstein. Frankenstein does not notice the substitution and implants that brain into the body of the monster, and then animates it using electricity.

The example of this creature is illustrative; a dead brain receives a second life in a body assembled from parts of the bodies of many different people. The brain, intrinsically singular and simple, is qualitatively different from the rest of the body, which can be assembled from parts, precisely because it is not inextricably connected with the personality. It is placed into the body like a soul, and plays a similar role in its life, animating and controlling an otherwise lifeless body. If the soul was once the helmsman of the ship of the body, then the helmsman now is part of the body - the brain - but, with the power of science, the brain like the soul, is potentially separable from its bodily 
confines. Thanks to the divine order of the world, when the immaterial soul loses its body, it leaves this world and passes onto the other world in order to face the final judgement and be resurrected in a restored body for its eternal life. The brain, however, that new secular and material soul, may be transplanted from one body into another, younger body. Thanks to technological progress, the only limit to this procession of bodies lies in the degradation of the organic matter of the brain.

The brain is material, and its visible morphology, as Doctor Waldman states, underlies the traits, inclinations, and behavior of the associated person, and even the trajectory of its life. In the characters' view, the morphology of the brain functions as a kind of fate that will follow the brain into whichever body it is placed (Spivak 2010). ${ }^{3}$ Subsequent events, however, despite the murders committed by the creature, hardly confirm this supposed causal relationship between the "criminal" brain and its behavior, as the creature only displays cruelty in response to aggression.

The interpretations of the film presented in contemporaneous reviews, as well as in later ones written in the late twentieth century, are even more illustrative. As Fernando Vidal demonstrates, many of them facilitated the "cerebralization" of the narrative and placed the film within the framework of biological determinism (Vidal and Ortega 2011). According to these interpretations, the brain transplant plotline was introduced in order to explain the creature's cruelty through the brain it received, and thereby relieve Doctor Frankenstein of any guilt. The events of the film appear as a struggle, with a creature enacting a fate imposed on it by its transplanted brain, as well as the creature's own struggle with its own cruelty and predisposition to murder induced by its brain. It is such interpretations that contradict the film and read cerebral determinism into it, insistently presenting notions, which had become culturally accepted by the 1930s, about the connection between the brain and personality.

The narrative of a struggle against "neurofate" imposed by interpretations of a film made long before the zenith of the neurosciences would become the foundation of many other narratives as its influence grew. Frankenstein marked a new limit of biopolitical intervention in an individual's life, an intervention established and buttressed by the

3. Professor Preobrazhensky and Doctor Bormenthal hold the same views as those in Mikhail Bulgakov's novella Heart of a Dog (1925). The insistent idea of cerebralization, which proliferated during that era, was fueled in Russia by famous transplant experiments (those of Sergey Voronov and Sergey Brukhonenko), as well as the activities of the Institute of the Human Brain. 
development of brain research and the ideology of the cerebral subject. The connection between brain and person operationalizes the person for biopower. Manipulating the brain makes it possible to separate the person from the body, expanding the capability to "make live and let die"; it is now possible for life to be prolonged involuntarily (and, perhaps, indefinitely), even when the body perished. Both life and death, however, still depended on a single irreducible remnant of flesh - the brain - and biopower must contend with that capricious organ.

\section{Brain in a Vat}

At the same time as Frankenstein was released, science fiction saw the appearance of an even more emancipated brain, one existing separately from the body, maintained by life support systems. The "brain in a vat" refers to a brain kept in a vessel full of nutrient-rich fluid which receives oxygen, other necessary substances, and sensory data through tubes and wires. (At times, an entire living head has been used, as, for example, in Alexander Belyayev's 1925 science fiction novel Professor Dowell's Head). The idea of the brain in a vat was used quite fruitfully in scientific thought experiments. As early as 1929, Marxist historian of science John Bernal, in discussions about the essence of modern humanity and the means to develop it further, proposed imagining a network of interconnected brains kept alive by a flow of fresh blood (Bernal 1929). Since the 1960s, thought experiments involving extracted, shared, or transplanted brains became popular in the context of philosophical discussions about personal identity and the nature of consciousness.

Unlike scientific thought experiments, science fiction is not limited by the need to provide rigorous arguments in support of its statements and is not obligated to solve the problems it discusses or defend any particular theory. In Olaf Stapledon's aforementioned 1930 novel about eighteen different species of human beings, the Fourth Men are giant, artificially created super brains with vestigial bodies, and live in huge brain turrets, where they do nothing but cogitate. They communicate via "telepathy" - radiation emitted by symbiotic Martian microorganisms. These creatures' vital functions are supported by technological equipment and the Third Men, who originally created them in an effort to "produce a man who is nothing but a man" (Stepldon 2004, 235). In their view, the primary attributes of a man were mental activity and its associated organs - the brain and the hand. While technological devices could surpass the hand, they contended that the 
brain could not be surpassed; hence it became the essence and body of the new species, so that it could help its creators understand the nature of immortality. (In this novel, Stapledon, who was an atheist, developed a unique cult that worshiped life itself). It must be noted that the Fourth Men never achieved their goal, although they did manage to learn a great deal. In fact, they exhausted their opportunities to learn, and, as they were incapable of anything else, began to hate their creators, who still had access to the joy of life. Ultimately, the storyline ends with the annihilation of the Third Men and the extinction of the super brains.

The brains in vats presented in many pieces of science fiction are surprisingly active, considering their lack of bodies, and are often demonized (while at the same time markedly and unnaturally increasing in size). There are many villainous brains: the alien brain Krang in the animated franchise Teenage Mutant Ninja Turtles (launched in 1988), the alien brain, named Gor, in The Brain from Planet Arous (1957), Martian brains in Mars Attacks (1996), the brain of a millionaire named Donovan in Donovan's Brain (1953), the arachnid leader in Starship Troopers (1997), Stapledon's Fourth Men, etc. . . Similar to medieval demons, such brains plan to conquer or destroy the world and subjugate all living creatures. Rather paradoxically, it is the most human thing about a human being, the organ closest to a person, in which the self is notionally rooted, that comes under suspicion and is distanced from the viewer (sometimes by being alien in origin). This is facilitated by their naturalistic appearance - a wrinkly, slimy ball of fat floating in fluid - but that does not tell the whole story. A brain without a body is perceived as the ability to think and cognize, taken to the extreme and abstracted from everything else. Without a body, it lacks the capacity to manifest human joys, failings, or the emotions traditionally attributed to the "heart." Attempts to produce distilled human essence, in fact, release the capacity for evil hidden within and eradicate the actual human element. After centuries of viewing the body with scorn and glorifying the soul (and after the Renaissance, the rehabilitation of the flesh), neurocentrism's elimination of the body and glorification of the brain looks like a secular, rather than religious, attempt to separate man from the living material world.

\section{Altered Carbon: The Brain of the Neo-Catholics}

A radical separation of man from the material world would involve transporting the personality beyond the bounds of body and brain. In 
many religious doctrines, the Abrahamic ones included, this was accomplished via the soul, but now it is embodied in the idea of uploading consciousness onto some material medium (so called mind uploading). This concept simultaneously continues and finalizes the idea of the cerebral subject. Since the ideology of the cerebral subject is relatively dependent on the neurosciences, it can be finalized. The salient point is that one of the radical possibilities or promises of contemporary brain research, perhaps even its "logical endpoint," is full brain mapping, identifying neuronal connections and patterns, all of which can then be digitized and uploaded to a computer (Sandberg and Boström 2008). Taken to the extreme, this could mean that it would be possible for a consciousness to live in a real or virtual world, without an organic body and brain. This pushes personality transfer a step beyond brain implants because it dislocates the somatic boundaries of the personality, fully liberating it from its temporal flesh.

The idea of uploading a consciousness onto a digital medium has a solid tradition in science fiction. It can be found in one form or another in the works of science fiction writers, such as Stanisław Lem, the Strugatsky brothers, William Gibson, Poul Anderson, and Ian M. Banks. In cinema it has appeared in Ghost in the Shell (1995), XChange (2000), Avatar (2009), Self/less (2015), Replicas (2018), etc. . I It is now time to turn to the aforementioned cyperpunk detective series Altered Carbon (2018-present), based on Richard Kingsley Morgan's 2002 novel of the same name, since its plot deals with the adoption and ritualization of mind uploading technology, coming into conflict with the religious life of believers.

In the twenty-fourth century, when most of the series' plot takes place, humanity has colonized distant planets and artificial intelligence has long since become commonplace (one of the main characters, for example, an AI named Edgar Allan Poe, is a hotel building). While the world of this series is separated from ours by three hundred years, the resemblance is suspiciously similar. The key difference lies in the new possibilities that have been opened up thanks to appropriated alien technology. Artifacts, found in the ruins of an alien civilization on Mars and the other planets, were used to develop the technology to save a personality and set of memories ("digital human freight") onto a "disk" (or "cortical stack"), which can be transplanted into a new body. This disk is then implanted into the base of the skull. Implantation is compulsory for all citizens of the interplanetary state ("Protectorate") older than one year of age. In this world, personality digitization has become a routine social convention, and has thus in- 
fluenced and, in fact, redefined many social, economic, and political practices. It must be noted, however, that this technology's capabilities are limited; new bodies are expensive, so the ability to choose one, or to switch bodies, is only accessible to a few privileged individuals, who control the world from residences that float through the heavens. They are the only ones who can truly achieve technological immortality. In this sense, the series is a criticism of transhumanist futurism, which ignores the fact that any technology includes not only its capabilities, but also the material conditions of its introduction, distribution, and application. The society depicted in the series is an urbanized, post-capitalist one with high levels of social stratification. The state is also intertwined with corporations, and there are significant gray areas, where it turns a blind eye to their activities or even directly sanctions them.

The time that a personality and set of memories can be stored on a disk is limited only by its material characteristics, but the quantity of bodies and years lived is limited by a person's financial resources and psychological strength. After a person dies, either naturally or through violence, provided the disk has not been damaged, it can be implanted into another body, either one belonging to another person, a cloned one, or a synthetic one (in the show, bodies are called "sleeves" to indicate how readily they can be changed). Duplicating a person, that is, copying one's person onto one more disk, is punishable by the destruction of the original disk, a grave punishment given that as long as the disk is intact, there is a chance of returning to life. Only the destruction of the disk is true death, fully alienating death from the destruction of the organic body. Furthermore, being on a disk without a body can, to a certain extent, be called "existing," if not quite "living." As a result, the penitentiary system has dispensed with incarcerating bodies; individuals simply serve out their sentences on disembodied disks (the protagonist, Takeshi Kovacs, has just finished a 250-year sentence before the series begins). People, whose bodies have died and who do not have the money for a new one, also wait on their disks for their families to save enough to buy them some kind of body.

This alien technology opens up many opportunities. It is possible to travel between planets almost instantaneously by entering a new body on a new planet. Crime victims can "resleeve," that is, be resurrected in another body for one day in order to press charges against their murderer, say their goodbyes, or see their families. There is also a government stockpile of bodies that have been left empty due to people being incarcerated. These bodies are sold or rented out to people, 
who cannot buy a body for a relative. Bodies are also rented out for special occasions, such as holidays, family celebrations, etc. . . People also rent bodies in order to preserve their own in risky situations, or to facilitate instantaneous business trips to other planets. Furthermore, this world includes something like social welfare. Since the implantation of a disk is compulsory for all, and the fulfillment of this requirement is monitored by the state, a free sleeve is provided for victims of crimes, accidents, emergencies, and disasters. The body may not match the personality, however; for example, a little girl might be "resleeved" into the body of an elderly woman or a brutal criminal. Prisoners are also provided with a body from this stockpile when they have served their sentences.

There is another large pool of opportunities associated with virtual reality. It is possible to upload one's personality to the virtual world for various actions and events since what happens there is experienced as if it were real. For example, this capacity is used so that torture and interrogation are real but inflict no bodily harm. In this scenario, death is just the end of a round to be followed by a restart, and the cycle repeats endlessly. Thus, the only limit to torture, the resilience of the human body, has been removed, and the final alternative, death to put an end to suffering, has been taken away from the victims, making their suffering endless.

Neither the series nor the book describes the discovery of any other locus of the person than the brain. In other words, the great undercurrent of the contemporary Western world, the ideology of the cerebral subject, retains its power; the personality is realized on the basis of the substance of the brain. It is from the brain that it is copied onto a disk. As such, it is assumed that alien technology has realized one of the dreams of the neurosciences - the full mapping of all the neural connections in the brain, enabling them to be defined and digitized. ${ }^{4}$ It is interesting to note that humanity was able to realize the idea of mind uploading not through the systematic pursuit of scientific knowledge, but rather through the experience of a disruption or in-

4. Note that the series itself has internal contradiction that contravenes the idea of the cerebral subject that hardwires a particular brain to a particular consciousness. The disk containing a person copied from a unique brain in a single body can supposedly be implanted into any body, i.e. any person can be transferred to any brain. After this transfer, the person sometimes needs time to adapt to the body, but it is hardly likely that all of the neuronal connections are restructured during that time in such a way that they match the original brain. This inconsistency means that the series is either contradicting current knowledge of the brain, or that the alien technology includes the function of rapidly restructuring neuronal connections. 
trusion (the discovery and successful appropriation of someone else's knowledge and technology). Immortality and a change in the nature of death were not achieved by man, but were brought in from outside, as a gift or inheritance from a more advanced civilization that has since died out. (This is clearly a reference to the ufology-based interpretation of ancient mythological narratives, describing boons received as gifts from higher beings, who descended from the heavens).

This new technology, however, causes the body to lose its significance and become a commercial consumable (a "sleeve"). It is no longer a temple, as in, for example, Orthodox Christianity, nor is it a prison, as in Neoplatonism or Gnosticism. It is, to put it harshly, an optional and, in fact, temporary residence and instrument for a person; its citadel is the disk, and, more broadly, the data transmission channels. It is possible to have experiences safely in the virtual world as well. Identity, however, is not in the least dematerialized or made to resemble the ancient idea of the soul. It is only the type of materiality which changes - it simply becomes computer equipment rather than organic matter. Liberated from the flesh by technical means, it becomes dependent on technology. That technology also goes on to define the boundaries of true death. Nonetheless, birth remains inextricably connected with the flesh, and a consciousness cannot emerge without a functional brain. The necessity of reproduction affirms the connection between man and the body. This technology potentially offers the gift of immortality by cancelling out death, a topic so important for religious life. Death is quite literally moved beyond the bounds of the flesh, as it is not the destruction of the body, but the destruction of the disk.

It is important to note that corporations and the state appropriated this technology and added it to their arsenal of tools for interfering in individual lives. This is a serious change to the character of biopower itself. In Foucault's interpretation, the power of the sovereign was able to "take life or let live"; the subject's death was, itself, a manifestation of absolute power. Biopower, however, which took shape later, was just the opposite; it consisted of the ability to "make live and let die." It emphasized the cultivation, correction, and control of life and the management of its risks, uncertainties, and shortcomings. At the same time, death as the boundary of life becomes "the moment when the individual escapes all power, falls back on himself and retreats, so to speak, into his own privacy" (Foucault 2003, 248). Power no longer has anything to do with death and, in fact, allows it to disappear. In Altered Carbon, biopower resolves this shortcoming; thanks to the 
disks, they remove the connection between the death of an individual and bodily death, and thus put death back under state control, simply by removing it from the existence of individuals. Individual life loses the teleology that directs it towards death and instead hovers in a timeless vegetative state on a disk. They are literally kept alive "when, in biological terms, they should have been dead long ago" (Foucault 2003, 248). By splitting death into two forms, biopower can potentially force people to exist indefinitely, and thus provides the state with unlimited capacity to interfere in their lives. Importantly, this was achieved thanks to a radical leap in knowledge about the brain. By using this knowledge to reformat death, biopower inevitably comes into conflict with the concepts and practices of believers, for whom death is the central event both of God's creation and of their own personal lives.

One of the pressing social issues in the series involves how people of faith ("Neo-Catholics," in this case) view the technologized practice of extending life beyond the death of the body. The Neo-Catholics believe that after bodily death, the soul goes away into the other world, while the person, "resurrected" using the alien technology, no longer has one. In short, the disk saves information, but not the soul. The ideology of the Neo-Catholics is not laid out in detail in either the book or the series, but one can speculate as to why posthumous earthly existence is undesirable for a person, who has already lost his or her soul. A person like that is a kind of zombie that has consciousness and a mental life but has been deprived of an invisible essence that their existence should have. Without a soul, the person is removed from the sphere of divine justice and rewards, unable to post sin or merit to his or her "account," since he or she does not have one. This existence is a kind of gray area from the point of view of the divine audit. Yet, the soul that was once connected with that person has such an account, and sins can be added to it, though they are someone else's rather than its own; this could mean either actions taken by the person without a soul, or it could mean that this new soul allowed the creature, for which God is dead, to emerge. Digitizing the person and separating death from the body and attaching it to technological devices is incompatible with Neo-Catholic concepts about the connection between the soul and the body and the role of bodily death. Faced with the choice between universal, transcendental resurrection in restored bodies and inextricably technological investiture in artificial bodies or the bodies of strangers, they, as one might expect, elected to choose the former.

The Neo-Catholics have opposed the technologized public order and refused any manipulation of their disks after their passing and 
are the only people to do so since the last uprising against the Protectorate, two and a half centuries ago. As such, disks, belonging to people of faith, are covered with special coding that protects them from being implanted again. In the series, this coding is the only boundary protecting the Neo-Catholic desire for a true death from the nightmare of biopolitical immortality.

By the same token, however, when the plot of the series begins, the Neo-Catholics have failed in their struggle against biopower; after all, the limit of their demands is just a ban on manipulation of their disks, not the right to refuse having the disk implanted in the first place or to destroy it after bodily death has occurred. They demand that the difference between bodily and technological death be collapsed for them, rather than that it actually be imposed. Keeping the disks, however, means keeping the threat of what they fear most - being implanted after death. Furthermore, even the coding that protects them from further implantation ceases to be any kind of guarantee at the end of the first season, when Proposition 653 is passed, granting judges the authority to disregard religious coding and resurrect a murdered person to give testimony. The biopolitical regime gradually penetrates Neo-Catholic death and begins to appropriate it - decisively, by eliminating it.

I will assume (since the series says nothing to the contrary) that the nature of religion and religious life in the twenty-fourth century are not substantially different than they are in 2019. In practical life, religious doctrine about the soul generally coexists with the many achievements of science that have changed the concept of human nature (obviously conflicts and resentment occur, but it is generally limited to particular people of faith or religious organizations, such as the Jehovah's witnesses, who refuse blood transfusions). A single individual's life, combining heterogeneous discourses about nature with the associated ethical (in the sense described earlier) consequences, is only possible when they are mobilized in different situations and no irresolvable practical conflict arises between them. The series Altered Carbon demonstrates an example of such a conflict, in which practices springing from one discourse begin to contradict the fundamental concepts of the others.

People of faith, with rare exceptions, do not experience any particular difficulties with either recognizing the knowledge produced by the neurosciences (and, more broadly, accepting the ideology of the cerebral subject) or the practices of medical intervention in the activity of the brain that is derived from that knowledge. In the imaginary situa- 
tion presented in this series, however, a conflict arises due to the neurosciences undergoing radical development until they reach their "logical endpoint" - the invention (through discovery or appropriation) of the technology required to transfer a personality from the brain to a digital medium, which can then be implanted in any body. More specifically, this is a conflict between religious concepts and practices connected with death and biopolitical interference in the life of the individual that uses technology, which redefines the very nature of death, eliminating it for the sake of unlimited control over life. The Neo-Catholics oppose not scientific knowledge itself, or mind uploading technology and the potential to exist endlessly, but the utterly unrestrained biopolitical forces that exploit that technology to coerce individuals to live on and allow their lives to be appropriated. In this context, the possibility of an unlimited life is equivalent to unlimited interference by biopower. For the sake of salvation, Neo-Catholics protect the boundary of their lives - death - which involves opposing the power that strives to take this boundary away from them to impose an endless, controlled existence on them.

The decision to keep the boundary of their lives somatic and not technologize it makes the Neo-Catholics outsiders and even freaks in this technologized world. Furthermore, due to their vulnerability, the lives of believers approach "naked life." Neo-Catholics are especially vulnerable to murderers, since after their bodily death, they cannot be resurrected in another body to bear witness against their killer. Anyone can kill them and do so with a high probability of going unpunished. This vulnerability lays the foundation for the narrative's main element of intrigue. In the first season of the series, false religious coding enables the owner of an elite bordello to prevent girls, who the bordello's clients killed, from being questioned. The coding prohibits bringing them back to life for the purpose of giving testimony, and the mystery of their deaths remains entombed on their disks. The owner even blackmails the billionaire, who hires the main character, Takeshi Kovacs, to investigate his death, to lobby against the passage of Proposition 653 (since it authorizes judges to resurrect victims or supposed victims to give testimony, regardless of their religious affiliation). While designed to restore justice and protect NeoCatholics from the state of "naked life," this proposition takes a step towards stripping them of their last protection against biopower. In other words, in defending the integrity of their deaths and the hope of eternal life from technologized biopolitical interference in the life of all individuals, the Neo-Catholics are compelled to move closer to 
"naked life," but when the state sets about eliminating that condition, they lose their last protection against that technology. As such, people of faith in this series find themselves in a difficult position; they can either become outsiders and practically martyrs while they are alive, but maintain the hope of eternal life, or gain protection from violence and justice in this life but sacrifice eternal life and become subject to everlasting torment.

\section{Conclusion}

Despite its undoubted popularity, Altered Carbon was panned by many critics, who saw it as, if not the final sunset of the cyberpunk genre, then at least a dead end. It was charged with excessive exploitation of retrofuturist nostalgia, the objectification of female bodies, excessive and convoluted violence, a lack of new ideas, and executing the ideas it did have crudely (Baker-Whitelaw 2018; Britt 2018; Robertson 2018). The critics also challenged the future depicted in this series because it lacks many innovations that exist in the present. It is, however, perhaps precisely this lack of innovation, which enables viewers to relate to the world of the series, that is, it invites the audience to focus on one particular thought experiment. Here, admittedly with the help of aliens, the promises of contemporary neuroscience and the accompanying ideology of the cerebral subject are fulfilled; consciousness is separated from the brain and recorded on a medium, which can then be transferred to any body, and, as a consequence, the death of an individual is separated from bodily death. Biopower, having appropriated this capability and made it a universally required duty, strives to eliminate death in order to interfere without limitation - in the lives of individuals. As a result, this biopolitical meddling comes into conflict with religious (Christian, in the case of this series) concepts and practices in which death is the central event.

In taking a stand for the right to die and the right to end a controlled earthly life, the Neo-Catholics are marginalized. This case demonstrates that in life it is not discourses themselves that collide - they coexist splendidly in the head of one individual - nor is it privately chosen practices. Technologies, based on scientific knowledge of human nature that transform that nature, inevitably become an object of intense interest from biopower, and once it has appropriated them, they may become a barrier that displaces people of faith to the margins of society. 


\section{References}

Baker-Whitelaw, G. 2018. "Netflix's 'Altered Carbon' proves cyberpunk has failed to progress.” The Daily Dot, February 2, 2018. http://www.dailydot.com/parsec/alteredcarbon-cyberpunk-2018/.

Bernal, J.D. 1929. The World, the Flesh \& the Devil: An Enquiry into the Future of the Three Enemies of the Rational Soul. London.

Britt, R. 2018. “'Altered Carbon' and 'Blade Runner 2049' Don't Exist Because of Futurism. How cyberpunk aesthetics have eclipsed cyberpunk punch.” Inverse, February 5, 2018. http://www.inverse.com/article/40915-altered-carbon-blade-runner-netflixcyberpunk.

Dean, M. 2010. Governmentality: Power and Rule in Modern Society. 2nd Edition. London: Sage.

Foucault, M. 1997. "On the Genealogy of Ethics.” In Ethics: Subjectivity and Truth, edited by Paul Rabinow, 253-280. New York: The New Press.

Foucault, M. 2003. Society Must be Defended: Lectures at the Collège de France, 1975-76. New York: Picador.

Foucault, M. 2005. The Order of Things: An Archaeology of the Human Sciences. London, New York: Routledge.

Kuznetsov, V. Iu. 1993. "Filosofiia fantastiki, ili Fantastika kak fenomen kul'tury." ["Philosophy of fantastic fiction, or fantastic fiction as a phenomenon of culture"]. Volshebnaiagora (1): 269-274.

Kuznetsov, V. Iu. 2010. "Filosofiia fantastiki. K postanovke problem." ["Philosophy of fantastic fiction. Towards posing a problem"]. Filosofiia i obshchestvo 57 (1): 124140.

Kaplun, V. 2019. "Perestat' myslit' 'vlast" cherez 'gosudarstvo': gouvernementalité, Governmentality Studies i chto stalo s analitikor vlasti Mishelia Fuko v russkikh perevodakh." [“To stop thinking 'power' through the 'state': gouvernementalité, Governmentality Studies and what has happened with Michel Foucault analytics of power in Russian translations]. Logos 29 (2): 179-220.

Rabinow, P. 2002. "Midst anthropology problems." Cultural anthropology 17 (2): 135149.

Robertson, A. 2018. "Altered Carbon's Blade Runner rehash misses the point of cyberpunk." The Verge, February 12, 2018. http://www.theverge.com/2018/2/12/17004210/altered-carbon-netflix-blade-runner-aesthetic-cyberpunk-retro-futurism.

Rose, N. and J.M. Abi-Rached. 2013. Neuro: The New Brain Sciences and the Management of Mind. Princeton, NJ: Princeton University Press.

Sandberg, A., and N. Boström. 2008. Whole Brain Emulation: A Roadmap. Technical Report \#2008-3. Oxford: Future of Humanity Institute, Oxford University. http://www.fhi.ox.ac.uk/reports/2008-3.pdf.

Spivak, M. 2010. "Mozg otprav'te po adresu...”: Vladimir Lenin, Vladimir Maiakovskii, Andrei Belyi, Ėduard Bagritskii v kollektsii Moskovskogo institute mozga ["Send the brain at the address": Vladimir Lenin, Vladimir Mayakovsky, Andrei Bely, Eduard Bagritsky in the collection of Moscow brain institute]. Moscow: Corpus.

Stepldon [Stapledon], O. 2004. Poslednie i pervye liudi: Istoriia blizlezhashchego i dalekogo budushchego. Sozdatel' zvezd. [The last and the first men: a story of the near and far future. Creator of stars]. Moscow: AST.

Vidal, F. 2009. "Brainhood, Anthropological Figure of Modernity." History of the Human Sciences 22 (1): 5-36. 


\section{ARTICLES}

Vidal, F. 2011. "Fiction film and the cerebral subject." In Neurocultures: Glimpses Into an Expanding Universe, edited by F. Vidal, F. Ortega, 329-344. Frankfurt am Main and New York: PeterLang.

Vidal, F., and F. Ortega, eds. 2011. Neurocultures: Glimpses Into an Expanding Universe. Frankfurt am Main and New York: PeterLang.

Vidal, F., and F. Ortega 2017. Being Brains: Making the Cerebral Subject. New York: Fordham University Press. 